\title{
Ambientações sonoras contrastantes nas três primeiras Ilhas de Almeida Prado: Ilha dos nove vulcões, Ilha de pedra e Ilha de gelo
}

\section{Contrasting sound environments in the first three Ilhas by Almeida Prado: Ilha dos nove vulcões, Ilha de pedra e Ilha de gelo}

\author{
Gregório dos Santos Oliveira \\ Universidade de São Paulo \\ Adriana Lopes Moreira \\ Universidade de São Paulo
}

Resumo: Em Ilhas, Almeida Prado apresenta diferentes blocos sonoros referenciais para cada uma das peças, junto a um curto texto descritivo, formando uma espécie de prefácio. Essas alturas são utilizadas sempre em sua oitava original e a essa permanência abre espaço para a percepção da interação das ressonâncias com a textura. À carga simbólica em cada uma das peças correspondem diferentes estratégias composicionais, fundamentando, assim, o interesse e a coerência na obra. Neste artigo, propomos uma análise das três primeiras peças, Ilha dos nove vulcões, Ilha de Pedra e Ilha de Gelo, buscando evidenciar possíveis relações entre a estruturação musical e o material textual.

Palavras-chave: Música pós-tonal. Análise musical. Teoria musical pós-tonal. Almeida Prado. Ilhas, para piano.

\begin{abstract}
In Ilhas (Islands), Almeida Prado presents different referential sound blocks for each of the pieces, along with a short descriptive text, forming a kind of preface. These pitches are always used in their original octave and this permanence opens space for the perception of the interaction of resonances with texture. The symbolic charge in each of the pieces corresponds to different compositional strategies, thus grounding the interest and coherence in the work. In this article, we propose an analysis of the first three pieces, Ilha dos nove vulcões, Ilha de pedra and Ilha de gelo (Island of the nine volcanoes, Stone island and Ice island), seeking to highlight possible relationships between musical structuring and textual material.
\end{abstract}

Keywords: Post-tonal music. Musical analysis. Post-tonal music theory. Almeida Prado. Ilhas, for piano. 
MUSICA THEORICA Revista da Associação Brasileira de Teoria e Análise Musical 2020,

v. 5, n. 1, p. 178-195 - Journal of the Brazilian Society for Music

Theory and Analysis @ TeMA 2020 - ISSN 2525-5541

José Antônio Rezende de Almeida Prado (1943-2010) foi um compositor brasileiro bastante prolífico, tendo escrito mais de 600 obras para diferentes instrumentos e conjuntos instrumentais. Também conhecido por suas habilidades como improvisador, Almeida Prado frequentemente incorporava a experimentação ao piano em seu processo composicional. Isso se traduz em um gestual muito próprio, que articula diferentes timbres, texturas e ressonâncias em elementos que muitas vezes extrapolam a técnica e notação tradicional. Como observa Assis, "Em muitos momentos, o instrumento deixa de ser apenas o veículo de apresentação da estrutura musical e passa a ter um valor estruturante [...]" (Assis 1997, p. 3).

A obra Ilhas é formada por oito peças (Ilha dos nove vulcões, Ilha de pedra, Ilha de gelo, Ilha verde-azul, Ilha de coral, Ilha das flores, Ilhas afortunadas e Arquipélago) e se insere em sua fase de exploração de sonoridades e consolidação da sua linguagem ${ }^{1}$. Nela, podemos observar algumas de suas características idiomáticas ainda em formação, como a utilização de segmentos de coleções referenciais organizados enquanto "blocos sonoros" (Assis 2013) - aqui denominados "blocos sonoros referenciais" -, e a associação com temáticas não-musicais².

Em Ilhas, Almeida Prado apresenta diferentes blocos sonoros referenciais para cada uma das peças, em uma espécie de prefácio. A escolha desses blocos acontece pelo seu potencial de ressonância ${ }^{3}$, através da escuta e experimentação ao instrumento. Esses blocos estáticos são articulados de acordo com o conteúdo textual das epígrafes descritivas de cada uma das Ilhas, cujo contraste reflete

\footnotetext{
1 Almeida Prado divide sua obra em sete diferentes fases estilísticas, como apresentada por Corvisier (2015, p. 7): Anos de aprendizado (1952-1959); Influência do neofolclorismo de Camargo Guarnieri (1960-1965); Aulas particulares com Gilberto Mendes, exploração do serialismo (1965-1969); Influências de Messiaen, Ligeti, Penderecki e Stockhausen (1969-1973); Consolidação de sua linguagem composicional, períodos astronômico e ecológico, exploração de novas sonoridades, transtonalidade (1973-1983); Pós-modernismo, pluralismo e ecletismo, colagens e citações como meios de expressão musical (1983-1993); Síntese, período tonal livre (1994-2010). Moreira (2002) propõe uma classificação diferente, que as agrupa em quatro fases Nacionalista (1960-1965), Pós-tonal (1965-1973), de Síntese (1974-1982) e Pós-Moderna (19832010) - e cinco temáticas - Mística, Ecológica, Astrológica, Afro-brasileira e Livre.

2 Adotamos neste trabalho a diferenciação elaborada pela filósofa Lydia Goehr (apud Bonds 2006, p. 114) entre objeto não-musical, como algo que existe a priori fora da música (um texto, quadro, objeto, sentimento), e extra-musical, como o objeto que nos é remetido através da música.

${ }^{3}$ Informado pelo compositor a Adriana Lopes Moreira em comunicação informal.
} 
diretamente nas diferenças motívicas e estruturais, modulando em cada peça a carga simbólica bastante rica que a temática das Ilhas representa para Almeida Prado.

O potencial subjetivo e poético do componente textual abre espaço para soluções musicais inovadoras, evidenciadas pelo tratamento expandido do instrumento. Sendo um ciclo de peças contrastantes, o mapeamento sonoro do conteúdo não-musical se torna ainda mais notável. É um recurso que

atribui aos sons o poder de evocar uma realidade externa, de descrever o visível ou, mesmo, de contar uma história; contudo, um poder ilusório, pelo menos excessivamente limitado, que recorreu muitas vezes a um texto extramusical, escrito ou lido, que impõe ao público um "conteúdo". [...] Entretanto, uma coisa é certa: esta concepção não sobrecarrega absolutamente nada a estrita qualidade musical da obra [...]. Pelo contrário, desempenha aqui um papel de primeira importância, libertando a forma dos seus esquemas preestabelecidos (Boucourechliev 2003, p. 123).

Na Fig. 1, apresentamos o material pré-composicional da primeira peça, Ilha dos nove vulcões ${ }^{4}$ :

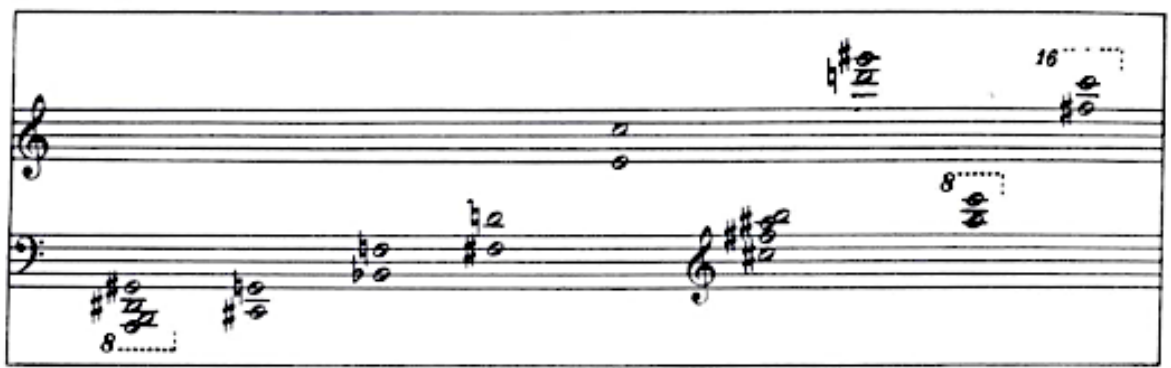

\footnotetext{
Ilha dos nove vulcôes

Densidade ignea, sangue da terra, explosảo de ritmos incandescentes, estranha liturgia de violéncia, um canto scvalgem entre as lavas e o mar.

L'ile de neuf volcans

Densite de feu, ung de la terre, explosions de rythmes flamboyants, étrange liturgie de violence, un chant sauvage entre les laves et la mer.

Insel der 9 Vulkane

Feuerspeiend. Blut der Erde, Explosion glühender Khythmen, seltsame Liturgie der Heftigkeit, wilder Gesang zwischen Lava und Meer.

The island of nine volcanoes

Spitting fire, the blood of the earth, explosions of incandescent rythms, a strange liturgy of violence, a wild song between lava and sea.
}

Figura 1: Prefácio da peça Ilha dos nove vulcões, de Almeida Prado.

\footnotetext{
${ }^{4}$ No prefácio da partitura publicada pela Tonos Musikverlag, o título desta peça aparece como Ilha dos nove vulcões; porém, antecedendo o primeiro sistema, lê-se Ilhas dos nove vulções. Optamos pela versão do prefácio, por alinhar-se com os títulos das demais peças.
} 
Em Ilhas, esses blocos sonoros referenciais são utilizados sempre em sua oitava original, sendo combinados em diferentes gestos, motivos e texturas. A escolha dessas sonoridades está vinculada ao seu potencial de gerar diferentes zonas de ressonâncias, mais tarde classificadas por Almeida Prado (1985, p. 569570) como explícita (um "uso racional e organizado" da série harmônica superior e inferior, podendo haver notas invasoras), implícita (com notas "que se impõem como elementos constituintes das ressonâncias"), múltipla (um processo acumulativo de notas em que há uma mistura de ressonâncias), ou com pouca ressonância. Sendo assim, as ressonâncias do instrumento têm um papel estruturante nessa obra, conforme veremos mais adiante, sendo articuladas na obra de duas maneiras: através da oposição entre diferentes ressonâncias e através da oposição entre momentos de maior e menor ressonância. A diferença entre as ressonâncias é criada através da manipulação da tessitura e do conteúdo intervalar das coleções, enquanto os momentos de maior ou menor ressonância são construídos através da do uso da tessitura, dinâmica, articulação e do pedal de sustentação.

Esses diferentes recursos composicionais procuram responder à modelagem sonora de ambientações geográficas:

Ilhas são situações-sonoras-estáticas, limitadas em sua concepção serial, como blocos sonoros, no caso tentando descrever ilhas sonoras, das mais diversas ambientações geográficas. É uma obra que tenta ser descritiva (Almeida Prado apud Assis 2013).

O uso de diferentes temáticas e elementos não-musicais em seu processo composicional é característica marcante na obra de Almeida Prado. Moreira (2002, p. 47-53) identificou cinco principais temáticas que perpassam suas diferentes fases cronológicas: mística, ecológica, astrológica, afro-brasileira e livre. Ilhas é uma de suas primeiras peças de temática ecológica, temática esta que tomou grande força após seu período de estudos em Paris (1969-1972), onde teve aulas com Nadia Boulanger e Olivier Messiaen.

Neste ambiente fui tentando compor obras que misturavam toda aquela base nacionalista, que já respirava um outro ar, com o que eu apreendia e as minhas raízes. Foi então que comecei a olhar em direção à fauna e flora brasileiras como fontes de inspiração, não utilizando mais o folclore, e sim a inspiração nascida dos bichos, das flores, das orquídeas, da Amazônia (Almeida Prado apud Corvisier 2000, p. 14). 
Apesar de trazer a temática ecológica como uma forma de afirmação da nacionalidade, esta frequentemente é feita a partir de uma visão mística da natureza. Isso é observado em Ilhas, que apesar de ter como inspiração inicial as ilhas fluviais de Cubatão, traz em seus títulos e epígrafes descrições fantásticas e poéticas, caracterizando ilhas fictícias.

Percebemos, então, uma referência ao nacionalismo em Ilhas, principalmente através da temática ecológica. Contudo, para Almeida Prado, a representação de "ilhas" como conteúdo não-musical já traz uma carga simbólica nacionalista, como é evidenciado em seu oratório Villegaignon, ou Les Isles Fortunées. Composto dois anos antes, em 1971, traz texto de Henri Doublier sobre a colonização da França Antártica, na Baía de Guanabara, por Nicolas Durand de Villegagnon. Nele, Doublier romantiza a crônica histórica, associando-a ao poema de Pierre de Ronsard sobre as lendárias Ilhas Afortunadas.

Esse sentimento nacionalista diagnosticado em Ilhas, contudo, já não diz mais respeito ao nacionalismo como vanguarda modernista. Ao deslocar a carga nacionalista do material musical para o conteúdo não-musical, Almeida Prado se afasta do modernismo andradeano e começa a moldar sua própria forma de afirmação nacional.

\section{Ilha dos nove vulcões}

Densidade ígnea, sangue da terra, explosão de ritmos incandescentes, estranha liturgia de violência, um canto selvagem entre as lavas e o mar (Almeida Prado 1973).

Ilha dos nove vulcões é a peça mais densa e rica do conjunto, criando uma ambientação que remete ao fogo dos vulcões. A acumulação gradativa das ressonâncias, a divisão em camadas e os motivos em ostinato marcam sua estrutura.

Para estabelecer a dimensão descritiva nessa peça, Almeida Prado utiliza diversas estratégias: através do ritmo (instabilidade, ausência de pulsação, figuras rápidas, acciaccaturas); através da forma (apresentação das coleções em acumulação do grave para o agudo, mimetizando o movimento de erupção; 
MUSICA THEORICA Revista da Associação Brasileira de Teoria e Análise Musical 2020, v. 5, n. 1, p. 178-195 - Journal of the Brazilian Society for Music

clímax; dissolução); e através das coleções referenciais (riqueza do material; sobreposição de intervalos dissonantes e consonantes; amplitude da tessitura) ${ }^{5}$.

As coleções de alturas pré-definidas são apresentadas na forma de acordes de 4 notas e intervalos simples, como vemos na figura 2.

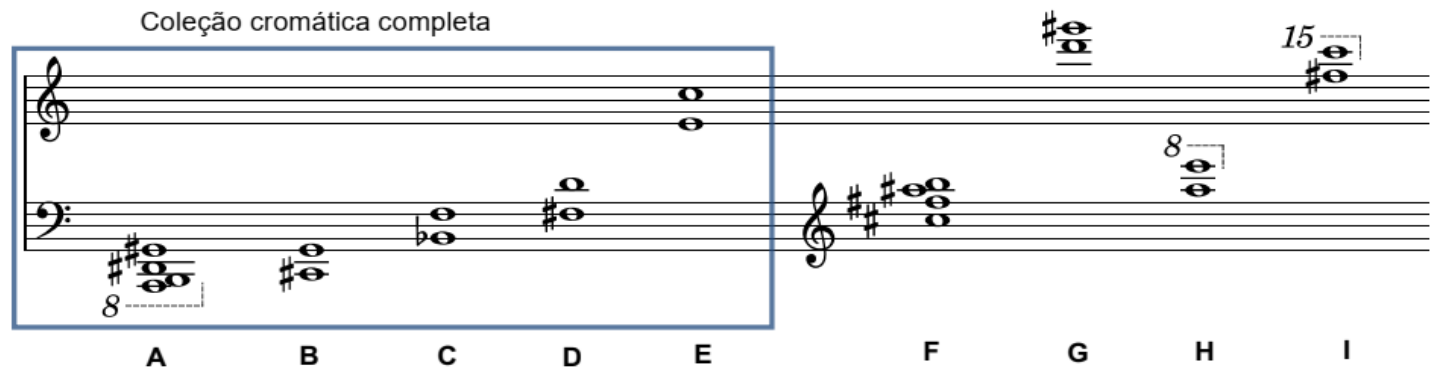

Figura 2: Blocos sonoros referenciais da peça Ilha dos nove vulcões, de Almeida Prado.

A peça se divide em duas seções principais (Tabela 1): a primeira, expositiva, apresenta as coleções de $\mathrm{A}$ a $\mathrm{H}$ progressivamente, distribuídas em duas camadas sobrepostas. A segunda é mais segmentada:

\begin{tabular}{|c|c|c|}
\hline \multicolumn{3}{|c|}{ SEÇÃO A } \\
\hline 1. & Sistemas $1-8$ & Exposição (coleções de A a H) \\
\hline 2. & \multicolumn{2}{|c|}{ Sistema 9Clímax da primeira seção/trillo (coleções F, G e H) } \\
\hline \multicolumn{3}{|c|}{ PONTE - Recapitulação/Redução da seção A (coleções A a H) } \\
\hline \multicolumn{3}{|c|}{ SEÇÃO B } \\
\hline 1. & Sistema 11 & Acorde (coleção A) + ostinato (coleções G, H e I) \\
\hline 2. & Sistema 12 & Acorde (coleção A) + ostinato (coleções F e G) \\
\hline 3. & Sistema 12 & Acorde (coleção A) + ostinato (coleções D, E e F) \\
\hline 4. & Sistema 13 & Acorde (coleção A) + ostinato (coleções G, H e I) \\
\hline 5. & Sistema 14 & Acorde (coleções D, E e F) + ostinato (coleções A e B) \\
\hline 6. & Sistema 15 & Dissolução, blocos sonoros referenciais \\
\hline 7. & Sistema 16 & Acorde (coleções A e F) + ostinato (coleção intrusa) \\
\hline 8. & Sistema 17 & Acorde (coleção intrusa) + ostinato (coleção intrusa) \\
\hline 9. & Sistema 18 & Dissolução, blocos sonoros referenciais \\
\hline
\end{tabular}

Tabela 1: Forma e caracterização das seções da peça Ilha dos nove vulcões, de Almeida Prado.

\footnotetext{
${ }^{5}$ Apesar de apresentarem diferentes técnicas composicionais, notamos uma proximidade de conteúdo não-musical com a peça Île de Feu I, dos Quatre Études de Rythme (1950) de Messiaen. Nela, Messiaen (1994) faz uma homenagem à Papua Nova-Guiné e a "toda violência dos rituais mágicos desse país".
} 
A seção A se articula através da oposição entre os dois estratos (ou camadas) da textura em multiníveis, evidenciados timbrísticamente através de diferenciações na dinâmica e nos tipos de $\operatorname{articulação~}^{6}$ (Fig. 3).

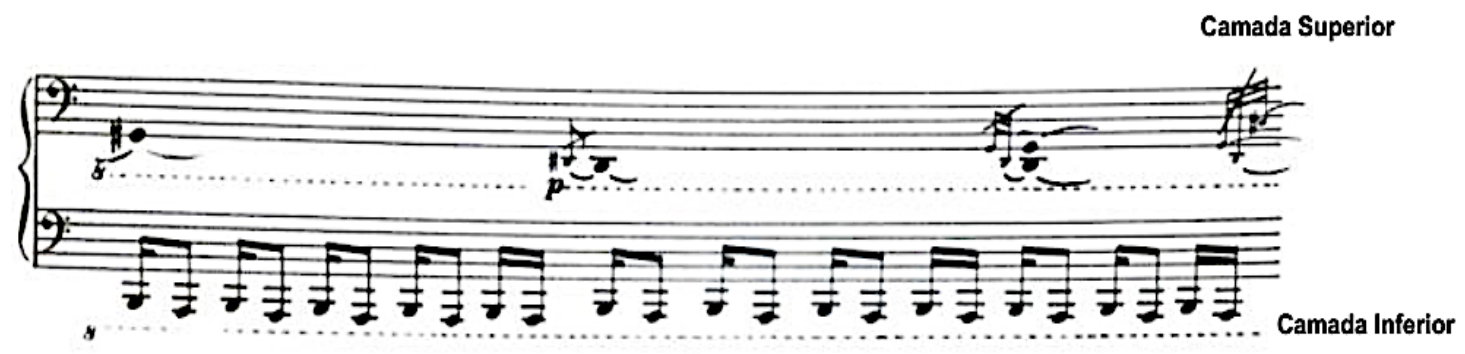

Figura 3: Duas camadas da textura em multiníveis na Seção A. Ilha dos nove vulcões, de Almeida Prado (sistema 2).

A camada inferior da Seção A (Fig. 3) tem um perfil textural construído através da iteração dos ataques na região gravíssima do piano com pedal aberto e dinâmica $p p p$. As alturas apresentadas na camada superior vão sendo integradas na inferior, formando um processo de acumulação das ressonâncias. Com a saturação da textura, percebemos cada vez menos os ataques discretos, deslocando a atenção da escuta para a oposição entre a ressonância gerada pelo trítono da camada inferior e os ataques da camada superior. A recorrência sempre variada da sobreposição de acordes sobre o trítono acaba ganhando um sentido motívico, de maneira que se reconhece o todo da seção nesses fragmentos e vice-versa.

A camada superior apresenta, gradualmente, as alturas das coleções referenciais, como podemos observar na figura 4. Essas alturas se destacam da camada inferior através da articulação, caracterizada pela figuração em acciaccatura, cabendo ao pianista intérprete marcar essa separação através da diferenciação dos ataques.

\footnotetext{
${ }^{6}$ Assis $(1997$, p. 33) percebe a separação em camadas como uma tentativa de mimetizar o "canto selvagem entre as lavas e o mar". Ela vê a camada inferior como um "som soturno, velado, misterioso do fundo do mar", sobre o qual ocorrem os "estouros periódicos das lavas de um vulcão".
} 


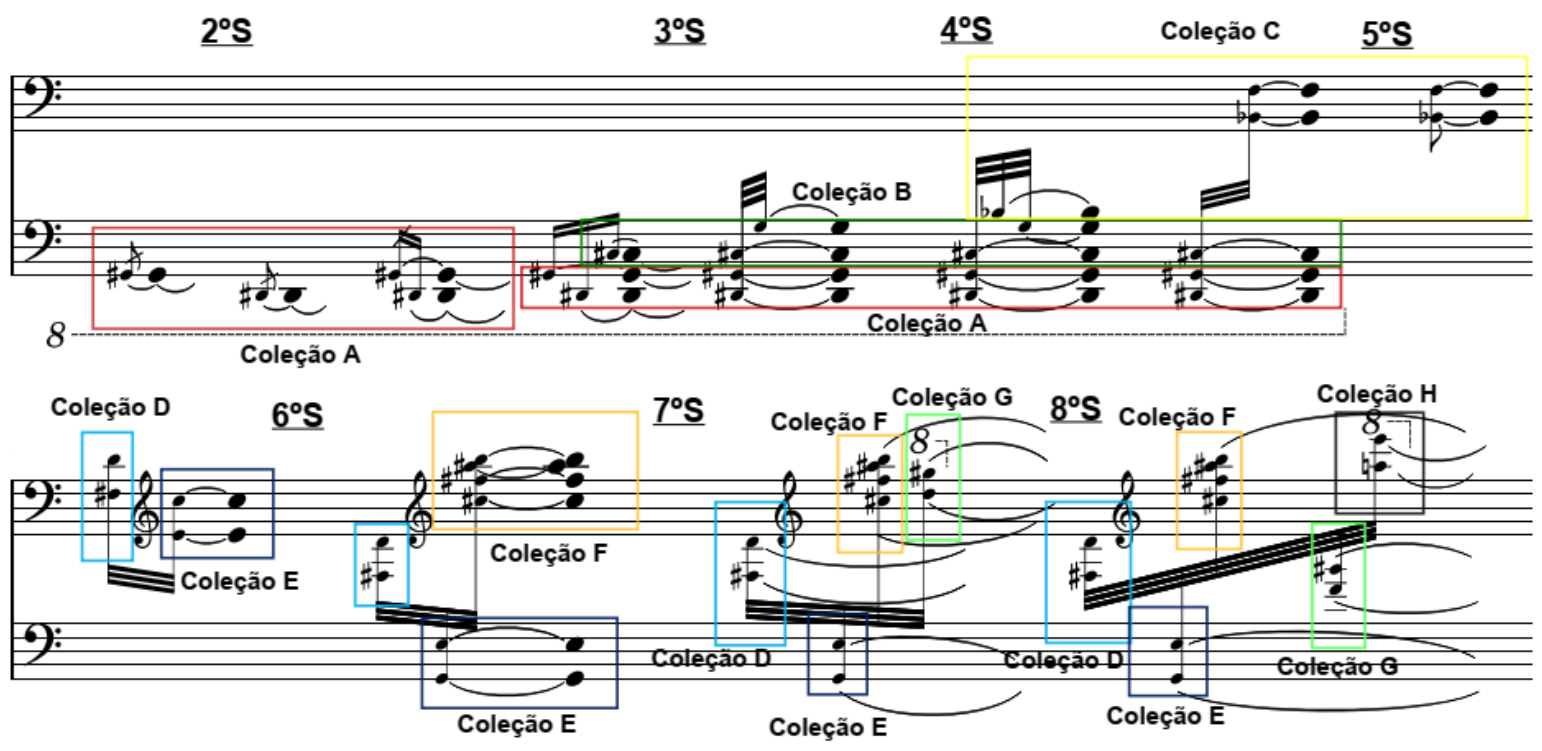

Figura 4: Camada superior da textura em multiníveis na Seção A. Ilha dos nove vulcões, de Almeida Prado (sistemas 1 a 8).

Esse padrão se mantém em um processo de acumulação que caminha em direção ao clímax da seção. Ele é alcançado através de duas ondas ascendentes que cobrem quase toda a extensão do teclado, culminando nos trillos nas coleções F, G e H. Esses trillos são sobrepostos à ressonância acumulada, em dinâmica $p$, e soam como uma tentativa de manipular os harmônicos sustentados (Fig. 5), antecipando o que ele chamará de "zona de ressonância implícita" (Almeida Prado 1985, p. 569-570). Esse é um procedimento importante na peça, pois busca superar a limitação do instrumento que é a incapacidade de manusear a sustentação das alturas após o ataque.

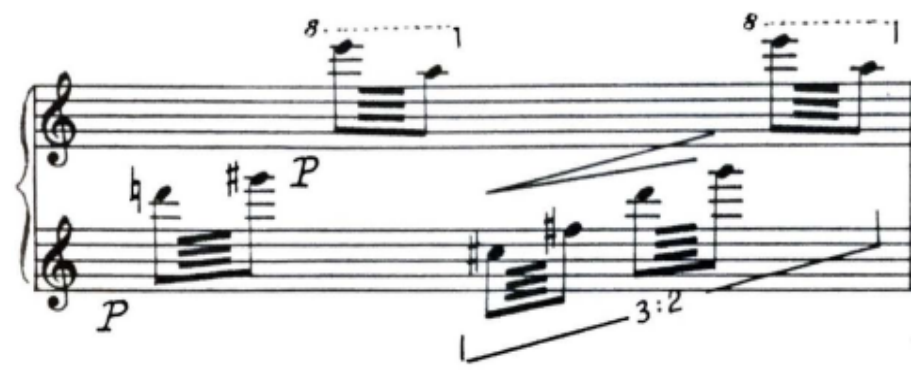

Figura 5: Sobreposição de trillos à ressonância acumulada na Seção A. Ilha dos nove vulcões, de Almeida Prado (sistema 9). 
A seção A mimetiza o processo de ativação do vulcão, através da intensificação da densidade, ressonância e dinâmica, e da acumulação das diferentes coleções em um movimento ascendente. Esse movimento resulta na primeira erupção, o clímax, que é seguido pela recapitulação condensada de A. Essa recapitulação marca a passagem para a próxima seção.

A seção $B$ dá continuidade às erupções, agora representadas através de um novo motivo (Fig. 6).

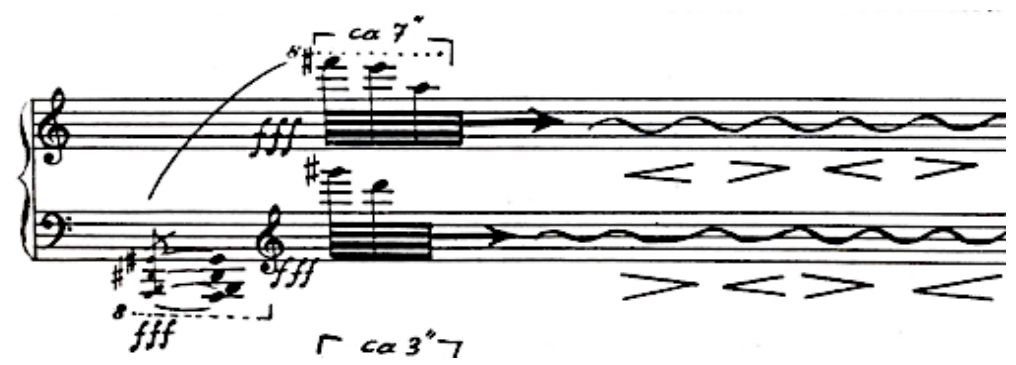

Figura 6: Motivo da Seção B. Ilha dos nove vulcões, de Almeida Prado (sistema 11).

Esse motivo faz um uso bastante original da ressonância, que mantém sua energia através dos ataques em fff da coleção A, no extremo grave do piano. Sobre essa ressonância são sobrepostas as coleções mais agudas, que, através de um ostinato de figuração rapidíssima, se misturam com os componentes da ressonância do acorde grave. Além do tratamento da ressonância, outro efeito interessante é a sensação de espacialidade, criada através da alternância de dinâmica entre as duas mãos. A sobreposição intercalada entre as coleções emula uma circularidade, como se o som estivesse fisicamente em movimento.

Na quinta aparição do motivo ele é modificado, trazendo no acorde atacado coleções na região média (D, E e F) e invertendo as graves (A e B) para o ostinato. Isso provoca uma mudança drástica na textura, pois o acorde atacado passa para uma zona de pouca ressonância do instrumento, e o ostinato, na região gravíssima, passa a apresentar dinâmica $p p$. Contudo, a coerência motívica, que é mantida através da articulação e configuração rítmica, atenua o choque dessa mudança.

Essa simples inversão da posição das coleções no motivo é uma ferramenta formal importante, pois alivia a textura e encaminha a peça para sua dissolução. 
MUSICA THEORICA Revista da Associação Brasileira de Teoria e Análise Musical 2020, v. 5, n. 1, p. 178-195 - Journal of the Brazilian Society for Music

Almeida Prado aproveita a coesão do motivo para introduzir algumas alturas "intrusas"7, que aparecem nas duas últimas apresentações do motivo. Essas alturas intrusas não fazem parte de nenhuma coleção referencial, e apresentam pouca ou nenhuma similaridade com elas. Essa quebra na rigidez da técnica composicional pode ser vista como mais uma estratégia de dissolução do material.

O material intruso é intercalado pelas duas apresentações literais das coleções referenciais, que interrompem o fluxo rítmico e dinâmico da peça e marcam a morte do vulcão (Fig. 7).
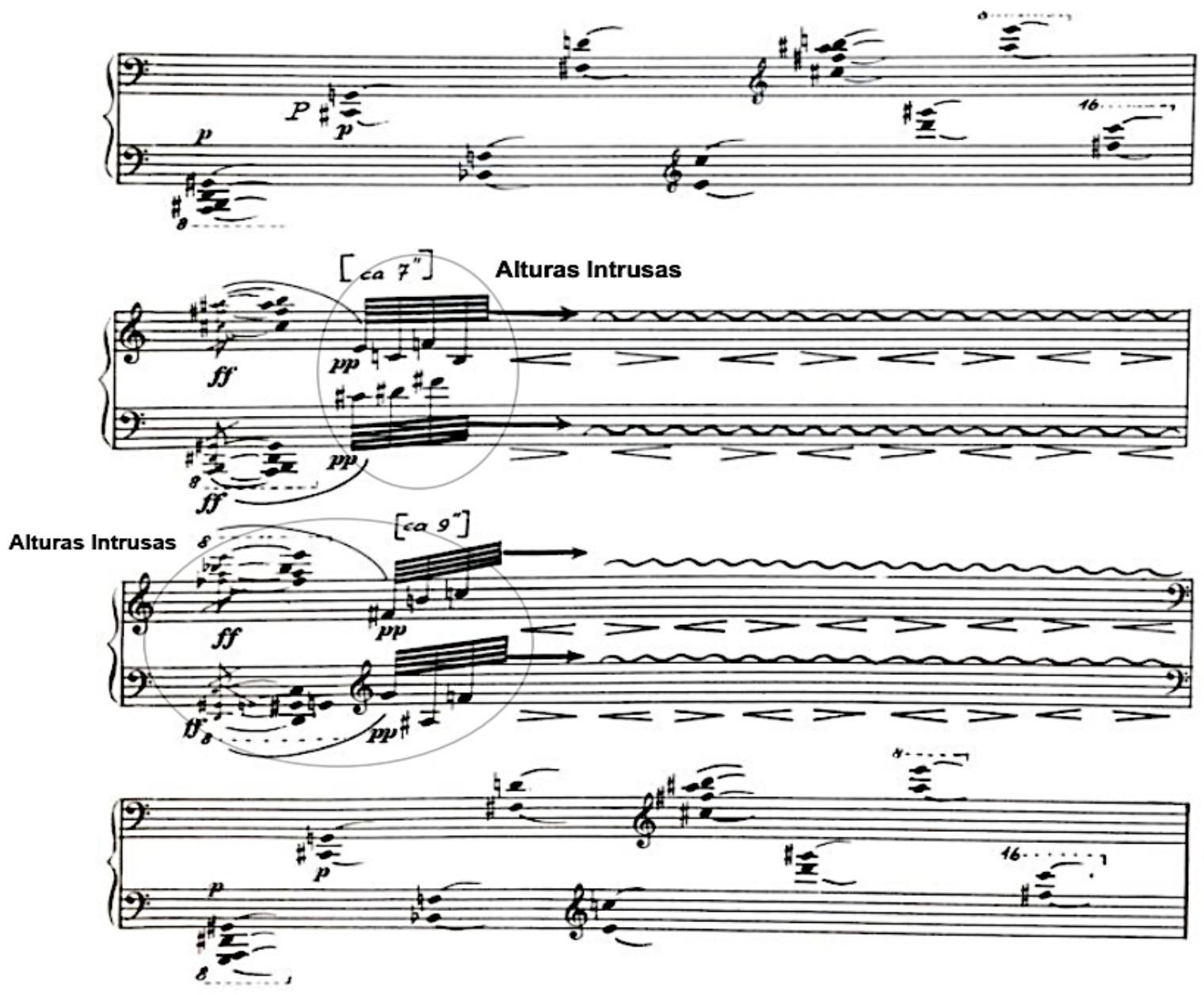

Figura 7: Alturas intrusas e blocos sonoros referenciais. Ilha dos nove vulcões, de Almeida Prado (sistemas 15-18).

\footnotetext{
7 Almeida Prado, em suas aulas, chamava a introdução de alturas externas aos blocos sonoros referenciais de "elementos invasores".
} 
Vemos em Ilha dos Nove Vulcões como Almeida Prado, dentro de um universo limitado de alturas, utiliza diferentes estratégias para caracterizar a ambientação da peça e criar uma estrutura narrativa. A seção A representa a ativação do vulcão, através da acumulação gradual das ressonâncias em um movimento ascendente. Essa acumulação resulta nas erupções, que são representadas na seção B pelo motivo destacado. O motivo sofre então diversas variações, perdendo força e ressonância, encaminhando o vulcão para o estado dormente. A aparição das coleções referenciais atacadas em piano soa como um último respiro, como a nuvem de cinzas remanescente das erupções.

A ausência de estruturas melódicas ou harmônicas desloca a importância estrutural da peça para o tratamento timbrístico e gestual das coleções.

\section{Ilha de pedra}

Aridez, silêncio, estranhos animais percorrem as ásperas escarpas. Abismos, nenhuma vegetação que traduza beleza, alguns arbustos de magra consistência, e um calor implacável (Almeida Prado 1973).

A Ilha de Pedra traz uma proposta de ambientação bem diferente da primeira peça, e isso se reflete já nos blocos sonoros referenciais. Enquanto Ilha dos nove vulcões apresentava nove diferentes coleções, Ilha de pedra traz apenas uma, na forma de um hexacorde (Figura 8). Apesar de aparecer na introdução como apenas um acorde, durante a peça ele é articulado em dois blocos divididos entre as mãos, seguindo a divisão da pauta.

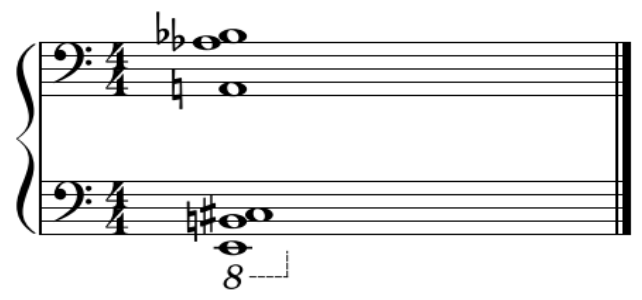

Figura 8: Bloco sonoro referencial da peça Ilha de pedra, de Almeida Prado. 
Ilha de Pedra não busca construir a representação descritiva através de uma estrutura narrativa, mas através do caráter e ambientação da peça ${ }^{8}$. Isso se reflete na textura mais enxuta, nas longas pausas, ressonâncias sustentadas e intervalos dissonantes.

A estrutura formal é bem clara, sendo dividida em duas grandes seções que são caracterizadas pelos motivos utilizados. A primeira seção traz uma textura polifônica em contraponto imitativo entre as mãos, que são intercalados por momentos de sustentação da ressonância (Figura 9).

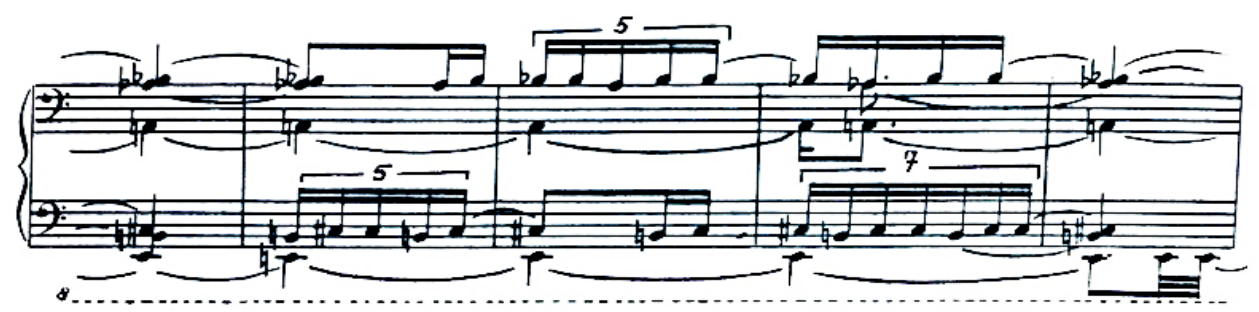

Figura 9: Contraponto imitativo. Ilha de pedra, de Almeida Prado (comp. 7-10) e sustentação da ressonância (comp. 11).

O movimento ocorre através das $2 \mathrm{M}$ presentes nas coleções, em uma figuração de quiálteras e semicolcheias que resultam em polirritmia. Esse motivo é repetido ao longo da seção com pequenas variações rítmicas, sempre mantendo a dinâmica em ff. A invariância da dinâmica, a constante quebra do movimento e a ausência do acento métrico no tempo forte dão a essa seção uma falta de direcionalidade. A polirritmia, o movimento em segundas e a estagnação ajudam a criar a aridez e aspereza da sonoridade, compondo assim a ambientação descritiva nessa primeira seção.

A passagem para a próxima seção se dá através de um arpejo em acciaccatura, apresentando as seis notas da coleção referencial. Após a segunda aparição do arpejo, Almeida Prado introduz duas novas alturas que são estranhas à coleção, Ré e Mib, sendo o Ré a nota mais grave da peça. Elas são atacadas na região gravíssima do piano, em repetição numa figuração rapidíssima e em polirritmia, como mostra a Figura 10.

\footnotetext{
8 Assis (1997, p. 42) vê na dissolução da forma e no "grande decrescendo sonoro" uma representação do "calor implacável da ilha" como se este "fosse o responsável pela diluição do material".
} 


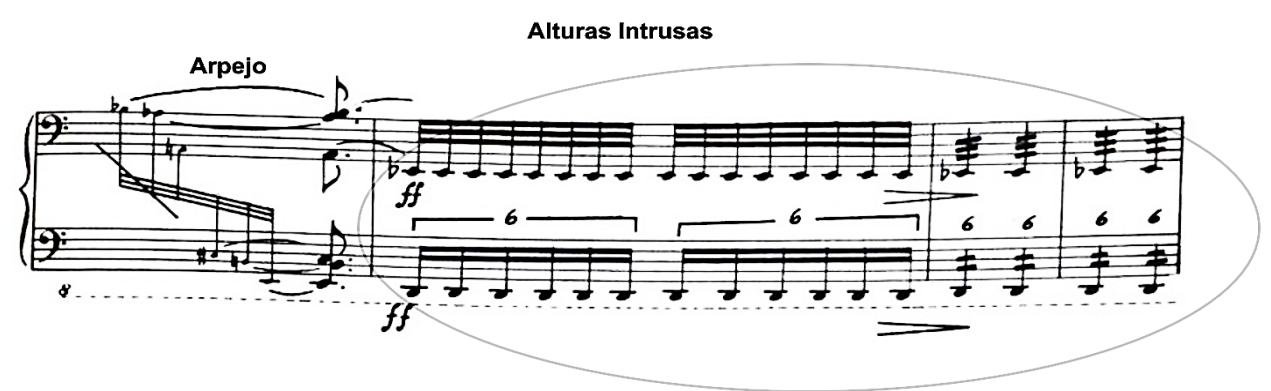

Figura 10: Alturas intrusas. Ilha de Pedra, de Almeida Prado (comp. 22-25).

A aparição dessas notas é destacada tanto pela mudança rítmica significativa como por ser um material novo e mais grave que o anterior. Almeida Prado utiliza a iteração das notas para fazer um decrescendo gradual em direção a suspensão em pausa, que mantém a ressonância através do pedal aberto. Essa sequência é transformada em motivo, que sofre diversas reduções até sua dissolução total no fim da peça.

O novo motivo tem uma textura linear, em um movimento descendente que vai dos componentes agudos da coleção referencial até as alturas intrusas (Figura 11).

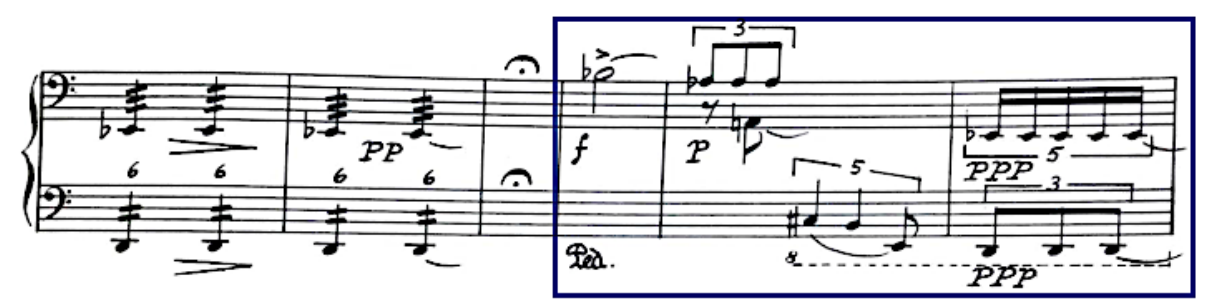

Figura 11: Motivo da segunda seção. Ilha de Pedra, de Almeida Prado (comp. 26-31).

A cada reapresentação o motivo perde força, reduzindo gradativamente a dinâmica e o número de notas, até sobrarem apenas as alturas intrusas (Figura 12). 


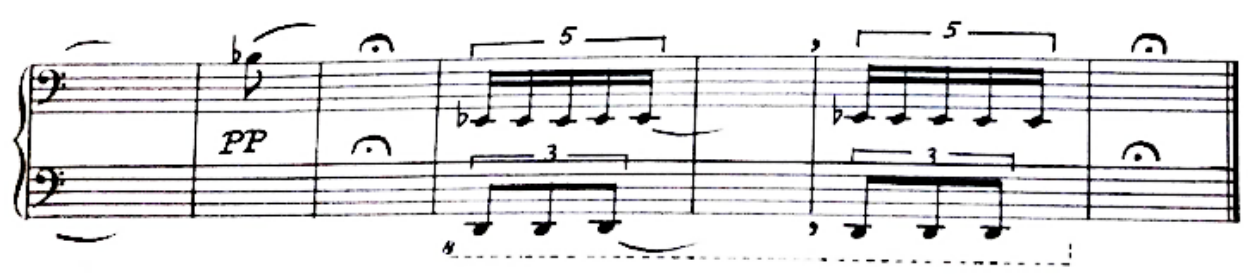

Figura 12: Finalização pelas alturas intrusas em Ilha de Pedra, de Almeida Prado (comp. 44-50).

Vemos então como Ilha de Pedra apresenta estratégias formais muito diferentes da Ilha dos nove Vulcões, diferenças estas que refletem a distinção entre os títulos e epígrafes. Enquanto a primeira Ilha trouxe uma riqueza de sonoridades e materiais em uma figuração instável e rápida, Ilha de Pedra revela a economia motívica em uma textura simples e entrecortada por pausas. Essa economia de materiais resulta em uma estrutura formal também simples, que dificulta a especulação de uma estrutura narrativa. Dessa forma, a dimensão descritiva fica a papel principalmente da sonoridade e ambientação da peça.

\section{Ilha de gelo}

Iceberg, flutuando qual navio branco cristal, majestade imaculada, impessoal, imenso, solitário (Almeida Prado 1973).

Ilha de Gelo se aproxima bastante da segunda, tanto através do conteúdo textual como musical. Apresenta três coleções referenciais, que são divididas na música em três camadas (Fig. 13).

O conteúdo intervalar dessas coleções é bastante dissonante, sendo A formado por um cluster de semitons e B e C apresentando intervalos de 11, 13 e 15 semitons. $\mathrm{O}$ conteúdo intervalar das coleções, combinado à dinâmica $p$ que se mantêm ao longo de toda a peça, gera uma ressonância pobre, pela ausência de reforço das parciais. Isso dá destaque aos ataques das alturas de B e C, que devido aos intervalos amplos e dissonantes adquirem uma sonoridade brilhante, principalmente nos componentes agudos das coleções. 


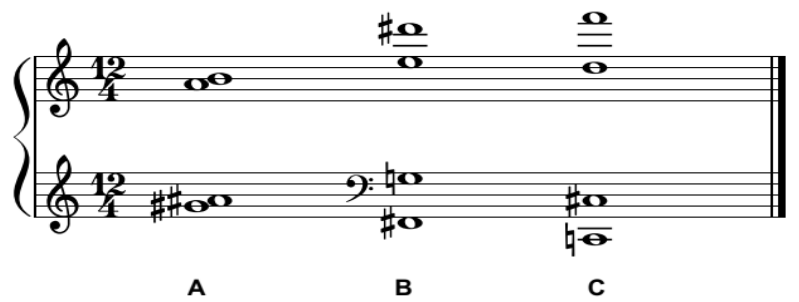

Figura 13: Blocos sonoros referenciais Ilha de Gelo, de Almeida Prado.

A peça se organiza através de um pedal em mínimas que apresenta a coleção A. Esse pedal se mantém sem interrupções até o final e é sobreposto pelos ataques das alturas das coleções B e C. Enquanto a coleção A é atacada sempre em sua configuração original, $\mathrm{B}$ e $\mathrm{C}$ são divididos entre seus componentes graves e agudos, que se alternam formando novos acordes. Apesar de variar a composição dos acordes, é a única peça do conjunto que não apresenta alturas intrusas.

Notamos que Ilha de Gelo mantém uma relação de intertextualidade com um dos prelúdios de Debussy, Des pas sur la neige. Além da relação não-musical entre neve e gelo, Des pas sur la neige apresenta uma semelhança estrutural, manifesta através da divisão em camadas, da utilização de ostinato em segundas na região central e da sobreposição de intervenções nas vozes grave e aguda.

Almeida Prado organiza os ataques através de uma figuração de quiálteras e pausas, imprimindo um caráter pós-tonal e acentuando a separação entre as notas pedal e as outras camadas.

Essa é a peça mais curta das Ilhas, compreendendo apenas quatro sistemas. Estruturalmente, ela consiste de uma seção única, que aumenta gradualmente em complexidade e frequência a interação entre as coleções B e C com o ostinato, em direção ao último sistema. Essa intensificação, contudo, acontece de forma sutil e não resulta em um clímax, não perturbando o caráter estático da peça. A ausência de contraste de dinâmica, textura, andamento ou formas de ataque traz a "sensação de que os elementos musicais 'não vão, simplesmente estão', como um 'iceberg' flutuando em torno de si" (Assis 1997, p. 49).

A partir do terceiro sistema, os ataques dos componentes graves e agudos passam a ser dessincronizados, reforçando a sensação da polirritmia e a tensão criada com as notas pedal. Após a breve intensificação, a peça cadencia em um movimento de fechamento, reduzindo a frequência das intervenções até cessar 
completamente. O pedal é atacado mais três vezes, dissipando o movimento da mesma forma que ele começou (Fig. 14).

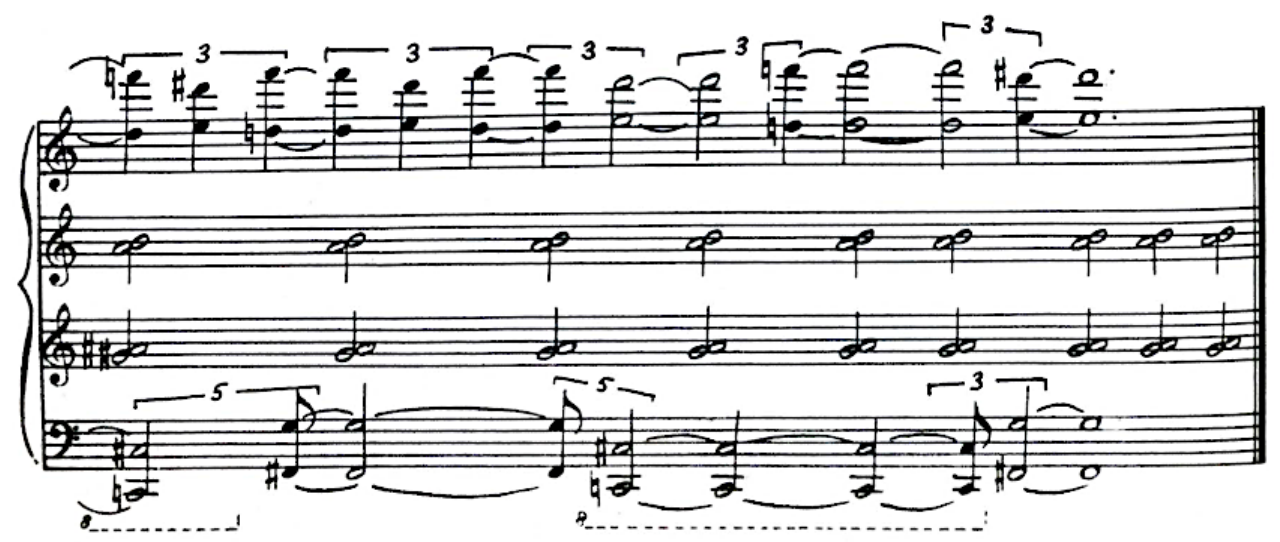

Figura 14: Finalização por ressonâncias das notas pedais. Ilha de Gelo, de Almeida Prado (sistema 4).

Assim como Ilha de Pedra, Ilha de gelo é marcada pela ausência de movimento e pobreza motívica. Monotemática, mantém o perfil de sobreposição do ostinato sem alterações. A estagnação do motivo e o uso do pedal, que sai do silêncio e volta ao silêncio, dá uma sensação de circularidade, como se a peça fosse apenas um recorte de um movimento que se dá infinitamente.

Os intervalos dissonantes mimetizam o estalar do gelo (Assis 1997, p. 50) e contribuem para a baixa ressonância da peça. A ressonância e a dinâmica contida destacam a terceira Ilha das anteriores, sendo a estratégia escolhida por Almeida Prado para representar o frio e a solidão sugeridos textualmente.

\section{Conclusão}

A limitação da notação tradicional para representar aspectos de toque e timbre frequentemente exige do compositor soluções criativas, criando uma dinâmica onde "articulações, marcações de tempo e textos poéticos extremamente específicos induzem o intérprete diretamente ao ato performático[...]"9 (Nonken 2014, p. 34).

\footnotetext{
9 "Highly specific articulations, temporal markings, and poetic texts engage the performer directly in the performative act, rather than merely providing basic indications of dynamic levels and tempi or standard terms for a general mood (appassionato, grave) to be evoked".
} 
A recorrência a conteúdos não-musicais como impulso criativo é frequente no repertório musical, sendo operada das mais diversas maneiras. Alguns exemplos notáveis podem ser observados entre os ciclos de Préludes de Debussy, e os Études Tableaux de Rachmaninoff. Enquanto Debussy revela o conteúdo programático ao final da peça, Rachmaninoff, apesar de manifestar a importância desse referencial externo como ponto de partida, não os revela ao intérprete ou ouvinte.

Almeida Prado faz questão de deixar registrado esse conteúdo na partitura, através das epígrafes dedicadas a cada uma das peças, junto aos blocos sonoros referenciais. A presença do texto anexo à partitura demonstra que Almeida Prado considerou o conteúdo relevante não só para o processo composicional, mas também para a execução.

Em Ilhas, vemos como o componente textual deixa de simplesmente circundar a obra e passa a modificar ativamente a estrutura do discurso. Além de servir como impulso criativo durante o processo composicional, o conteúdo nãomusical funciona como uma referência para o intérprete na construção da paleta de toques e timbres. Essa referência, contudo, devido à carga subjetiva do texto, não limita as possibilidades interpretativas. Pelo contrário, traz para o pianista um papel importante como co-criador da obra musical e aproxima o público através de uma abordagem multissensorial.

A análise musical por parâmetros estabelece uma interlocução com essa ampla gama de estímulos sensoriais, evidenciando estratégias composicionais circunscritas à atividade exclusivamente musical. Pensar a relação texto-música em Almeida Prado se mostra essencial não apenas para uma investigação estética, mas também interpretativa ou analítica.

\section{Referências bibliográficas}

1. Almeida Prado, José Antonio de. 1973. Ilhas para piano. Partitura. Darmstadt: Tonos International.

2. Assis, Ana Cláudia de. 2013. Ilhas de Almeida Prado: por uma paisagem sonora imaginária. Estúdio, Lisboa, v. 4, n. 8, p. 75-81. Disponível em: 


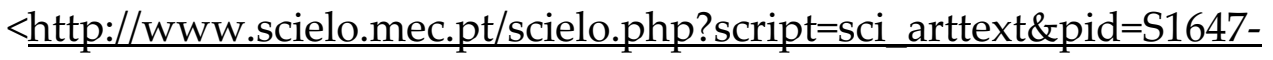
61582013000200009\&lng=pt\&nrm=iso $>$. Acesso em: 12 dez. 2020.

3. Assis, Ana Claudia de. 1997. O timbre em 'Ilhas' e 'Savanas' de Almeida Prado: uma contribuição às práticas interpretativas. Dissertação (Mestrado). Rio de Janeiro: Universidade do Rio de Janeiro, Centro de Letras e Artes.

4. Boucourechliev, André. 2003. A Linguagem Musical. Lisboa: Edições 70.

5. Bonds, Mark Evans. 2006. Music as Thought. New Jersey: Princeton University Press.

6. Corvisier, Fernando Crespo. 2000. The ten sonatas of Almeida Prado. Tese (Doutorado). Houston: Houston University.

7. Corvisier, Fernando Crespo; Costa, Thiago de Freitas Câmara. 2015. Almeida Prado - Integral dos Noturnos para piano, Vol. III. São Paulo: Editora Pharos.

8. Messiaen, Olivier. 1994. Petites Esquisses D'Oiseaux; Cantéyodjayâ; Quatre Études De Rythme; Pièce Pour Le Tombeau De Paul Dukas. Nota de programa. Koch International Classics.

9. Moreira, Adriana Lopes. 2002. A poética nos 16 poesilúdios para piano de Almeida Prado. Dissertação (Mestrado). Campinas: Universidade Estadual de Campinas, Instituto de Artes.

10. Nonken, Marilyn. 2014. The spectral piano: from Liszt, Scriabin, and Debussy to the digital age. New York: Cambridge University Press. 